\title{
El misterioso viaje de aprender a nadar, pensar y sentir: educación como proceso de creación de relaciones posibles
}

\author{
Alberto Moreno-Doña \\ Pontificia Universidad Católica de Valparaíso, Valparaíso, Chile. \\ Email: alberto.moreno@ucv.cl
}

\begin{abstract}
Resumen: ${ }^{1}$ El trabajo presentado es el relato de una experiencia educativainvestigativa de cinco años de duración cuyo foco ha estado centrado en el aprendizaje de la autonomía en el medio acuático, el desarrollo del pensamiento y la construcción de una relación afectiva. Se han considerado los principios de libertad, aprendizaje dialógico y mediación pedagógica, dirigidos todos desde la aceptación de la propensión a aprender de los infantes. El relato se ha construido en primera persona pues el autor coincide con el mediador pedagógico de la propuesta. Marcos, el protagonista del aprendizaje, construye un proceso de creación de relaciones posibles que le permite viajar, misteriosamente, interrelacionando la complejidad vital de diferentes dimensiones del ser humano: el pensamiento, las emociones y la motricidad.

Palabras clave: autonomía, propensión a aprender, mediación pedagógica, relacionalidad.
\end{abstract}

\section{The mysterious journey of learning to swim, think and feel: education as the process of creating potential relationships}

\begin{abstract}
This paper is the narration of a five year investigation/educational experience. The focus of this experience has been the learning process of autonomy on a swimming location, the thinking development and the building of an affective bond. The principles of freedom, dialogic learning and pedagogical mediation have been taken into account, always from the idea of a natural tendency in children to learn. It has been written in first person, as the author is also the pedagogical mediator of the proposal. Marcos, the child that goes through this learning, builds a process of potential relationships that allow him to go through a journey in which he can interrelate the vital different dimensions of human being: thoughts, emotions and mobility.
\end{abstract}

Key words: autonomy, natural tendency to learn, pedagogical mediation, relationality.

\section{A misteriosa viagem de aprender a nadar, pensar e sentir: a educação como um processo de criação de possíveis relacionamentos}

Resumo: O presente trabalho é o relato de uma experiência educativoinvestigativa de cinco anos de duração, cujo foco tem-se centrado na aprendizagem 
da autonomia no ambiente aquático, o desenvolvimento do pensamento e a construção de uma relação afetiva. Tem-se considerado os princípios da liberdade, aprendizagem dialógica e mediação pedagógica, todos dirigidos a partir da aceitação da propensão a aprender com as crianças. A narrativa foi construída na primeira pessoa, pois o autor concorda com o mediador pedagógico da proposta. Marcos, o protagonista da aprendizagem, constrói um processo de criação de relacionamentos possíveis podem permitir-lhe viajar, misteriosamente, inter-relacionando a complexidade vital de diferentes dimensões do ser humano: o pensamento, as emoções e o movimento.

Palavras-chave: autonomia, propensão para aprender, mediação pedagógica, relacionalidade.

$$
* * *
$$

\section{Contextualizando el trabajo}

El texto que a continuación se muestra es el relato de una experiencia educativa-investigativa focalizada en el aprendizaje natural y mediado ${ }^{2}$ de la autonomía en el medio acuático y su relación con el desarrollo del pensamiento y el apego entre educador y educando. Concluimos dicha experiencia después de cinco años en los que hemos querido dar cuenta de la genialidad que muestran los infantes al aprender (Marcos en nuestro caso), entendiendo este concepto como una condición consustancial al ser humano. Como diría Calvo (2012), el ser humano no puede dejar de aprender, a lo más puede aprender a no aprender, pero aún así sigue aprendiendo. El trabajo realizado se centró en un solo sujeto (Marcos), pero acompañado de su entorno familiar y la comunidad a la que pertenece.

Hemos introducido el concepto misterio, en el título de este artículo, a partir de algunas premisas centrales en nuestra propuesta educativainvestigativa, quizás cuestionable para otros profesionales, pero que nosotros consideramos fundamentales. A saber:

- Muchas de las cosas importantes en la vida no son enseñadas intencionalmente, pero igualmente se aprenden (Calvo, 2012)

- Estamos cegados y alienados por enseñar; olvidando el eje central del trabajo pedagógico: el aprendizaje (Moreno, 2006)

\section{Un primer cuestionamiento}

Nuestra primera intención ha sido intencionar una práctica educativa-investigativa orientada hacia el aprendizaje de la autonomía en el medio acuático. En mi condición de profesor de educación física, disciplina vilipendiada en los centros educativos por su carácter motor, separada de lo realmente importante (la mente), puedo decir cómo, a pesar de la injusta valoración que hemos recibido (Pastor, 2007) es también cierto que parte de esa desvaloración está anclada en que nuestro trabajo ha estado focalizado en aprendizajes muy instrumentales, espacio-temporalmente, pero poco 
importantes para el desarrollo de un sujeto consciente de sus derechos y deberes como ciudadano. Me refiero a enseñar, por ejemplo a: nadar, correr, saltar, bailar... No estoy queriendo decir que estos aprendizajes no constituyan parte relevante de una ciudadanía plena, pero sí que la forma descontextualizada en la que se han llevado a cabo no ha conseguido generar una conciencia crítica en relación a la importancia de construir un hábito activo de actividad física entre la población (López et. al., 2002). Ello, principalmente, por no ser capaces de generar una relación entre esos aprendizajes y otras dimensiones de esos seres humanos que aprenden (Moreno y Calvo, 2010)

Esta instrumentalización y descontextualización es acompañada, en este primer cuestionamiento, por una engañosa certeza epistemológica relacionada con el creer conocer cuándo aprenden las personas (Calvo, 2012). La única certeza que parecemos tener es que el contexto donde los niños y niñas se desarrollan condiciona, aunque no determina, el aprendizaje (Aubert et. al., 2010). Es por esta razón que el título de nuestro trabajo incluye el misterio. El misterio entendido como algo complejo de comprender, pero no por ello irreal, y como condición necesaria para sentir placer por el descubrimiento (Moreno, 2006). En nuestro caso concreto, el misterio está relacionado con cómo es capaz, un niño de cinco años, de aprender a ser autónomo en el medio acuático sin ninguna enseñanza explícita al respecto, y cómo ese aprendizaje puede estar relacionado con otras dimensiones: desarrollo del pensamiento y apego con sus seres más cercanos.

\section{Primeras referencias teóricas}

Entendemos el proceso educativo como el proceso de creación de relaciones posibles (Calvo, 2012), en contraposición al proceso de escolarización, que hemos constado, a partir de nuestras investigaciones, como un proceso de repetición de relaciones preestablecidas (Ibid). Cuando uno se educa, y lo hacemos constantemente, establecemos relaciones, verdaderas o no, posibles dentro de una infinidad de posibles relaciones. Normalmente, en el contexto escolar, nos dedicamos a repetir una serie de relaciones que ya otros hicieron por nosotros, pero no aquellas que, genuinamente, somos capaces de construir en y desde nuestra experiencia vital en el mundo.

Bajo esta conceptualización sobre lo educativo y escolar nos adentramos ahora en otro de nuestros referentes, la diferenciación realizada por Max Neef, Elizalde y Hopenhayn (1998) entre necesidades y satisfactores humanos. Las necesidades humanas son finitas y transculturales; lo que sí es múltiple, variado y condicionado culturalmente es la forma que tenemos de satisfacer dichas necesidades. A partir de aquí nace la inquietud central de este trabajo: ¿cómo podemos hacer que el aprendizaje se convierta en su satisfactor sinérgico de las necesidades humanas?, es decir, ¿cómo convertir el aprendizaje de la autonomía en el medio acuático en un satisfactor sinérgico de las necesidades de subsistencia, protección, afecto, entendi- 
miento, participación, ocio, creación, identidad y libertad?; ¿acaso no es esta la forma de poder construir una experiencia educativa que ya muchos han denominado como educación holística? (Calvo, 2012; Gutiérrez, 2007; 2010). Estamos convencidos, aunque no por ello cerrado a sugerencias y críticas, que la intencionalidad de un proceso educativo centrado en la mediación pedagógica puede ayudarnos a la construcción de ese proceso de creación de relaciones posibles que hemos mencionado (López de Maturana, 2009).

\section{Mis convicciones (sustento) como educador}

Todo educador, lo diga o no, posee una serie de creencias susceptibles de ser cuestionadas, pero que le dan sentido a su quehacer pedagógico y vital (Díaz et. al., 2010). En nuestro caso le dan sentido a nuestro viaje misterioso hacia la construcción de autonomía en el medio acuático. A continuación las explicitamos:

-La autonomía en el medio acuático de Marcos no es un aprendizaje a realizar sino un proceso que hay que re-vivir. Durante nueve meses todo niño se comporta autónomamente en el vientre materno. No entendemos la autonomía como un concepto interpretado bajo la capacidad de poder hacer algo solo, sino de ser capaz de hacer algo siendo consciente de la necesaria relación con los otros y lo otro. Sólo es posible incorporar a ese mundo propio aquello que es transformado según sus propios principios (Varela, 2000). Lógicamente esa autonomía en el vientre materno se da en la relación con la madre y en el acoplamiento estructural (Ibid) de los dos sistemas biológicos que existen en ese momento (madre e hijo). Esto tiene importantes consecuencias en mi labor como educador. Si asumo que esa autonomía en el medio acuático ya existía, estoy asumiendo que debo y puedo partir mi labor educativa por lo que Marcos sabe, y no por lo que ignora. No me interesa la restauración de lo viejo, me intereso en construir en capas sedimentarias, en la conservación de lo nuevo en la conservación de lo viejo. Para la conservación de lo viejo es buena la memoria (...) (Ortiz 2009:s/p). Entonces Marcos no tiene que aprender algo totalmente nuevo, sino recordar (establecer relaciones entre presente y pasado, proyectando el futuro) algo que ya poseía. Es desde el saber donde comenzamos a generar nuevos conocimientos, haciendo consciente las ignorancias que nos asaltan en el camino. Es desde la aceptación de los saberes de otro que ese otro se siente legitimado para aceptar sus propias ignorancias.

-El aprendizaje siempre se realiza de forma contextualizada. No hay mejor forma de enseñar algo que haciéndolo en su contexto real. Es, prácticamente imposible, aprender a montar en bicicleta escuchando hablar de cómo es la bicicleta y de qué hay que hacer para montar en bicicleta. El sentido común nos advierte de lo dicho, y la ciencia nos 
aporta hoy que en lo concreto es donde se da la experiencia humana. Varela (en Ojeda, 2001: 290), hablando de los avances de las diferencias ciencias, nos dice que lentamente han ido cobrando conciencia de que las cosas han sido planteadas al revés y han comenzado un radical viraje paradigmático o epistémico (...), la convicción de que las verdaderas unidades de conocimiento son de naturaleza eminentemente concreta, incorporadas, encarnadas, vividas; que el conocimiento se refiere a una situacionalidad (...) Lo concreto no es un paso hacia otra cosa, es cómo llegamos y dónde permanecemos. Dado lo dicho, una obligación que teníamos, si queríamos ser coherentes con esta afirmación, era que Marcos debía ponerse en contacto con el medio acuático a la brevedad posible. Fue el baño diario, entonces, lo que nos sirvió al respecto. La tina, el baño, debía constituirse, así, en una experiencia satisfactoria, lo que significaba que su mundo más cercano afectivamente debía estar presente. Es la tina el lugar donde seguir jugando con los padres, juguetes, lápices... Es así como la planificación educativa se convierte en un eje importante de la intencionalidad educativa (más adelante profundizaremos en ello). Una planificación que no debe eliminar la incertidumbre propia del misterio de cualquier viaje, pero debe mostrarnos un territorio por donde ir recorriendo algunos caminos (Calvo, 2012)

-El aprendizaje no se construye en un tiempo y lugar específicos. Todo proceso educativo es multiproxémico y policrónico (Calvo, 2012; Moreno, 2006), es decir, el aprendizaje de la autonomía en el medio acuático no termina en la piscina, el río o el mar. ¿Qué pasa después de esas experiencias en dicho medio? ¿Qué relaciones posibles se generan con otros contextos y tiempos que ayudan y/o dificultan el aprendizaje que estamos intencionando? Es por ello que estamos ocupados en cuidar no sólo esas experiencias concretas en el medio acuático sino también lo que ocurre antes y después en cuanto a las relaciones que Marcos realizaba.

-El aprendizaje se construye en comunidad. Para educar un niño hace falta la tribu entera (proverbio africano). Hacer realidad esta afirmación significa convertir los tiempos y espacios en públicos, no privados. Es decir, el encierro entre cuatro paredes no hace más que artificializar esa condición connatural del ser humano, la propensión a aprender (Calvo, 2012; López de Maturana, 2009). Es positivo y necesario que la gente (comunidad) entre al lugar de aprendizaje, critique, sugiera, y sobre todo colabore, pues entre todos/as facilitamos los procesos educativos (Aubert et, al., 2010). Es por ello que en nuestra propuesta los abuelos/s, tíos, amigos... son tan relevantes.

-Las emociones, positivas o negativas, no pueden quedar fuera del espacio-tiempo educativo. La mirada tradicional hace de la institución escolar la cárcel de los sentimientos (Santos, 2004: 47). El llanto, las lágrimas y la rabia, al igual que la alegría, son partes relevantes en la comunicación humana. Si entendemos el proceso educativo 
como proceso comunicativo dialógico (Aubert, et, al., 2010) se hace necesario legitimar esas emociones tan propias, aunque no exclusivas, del ser humano. Es desde las propias situaciones que vive Marcos desde donde abordamos y trabajamos nuestra intención educativa.

-Todo quehacer humano se da en el conversar y lo que en el vivir de los seres humanos no se da en el conversar no es quehacer humano (Maturana, 2006: 90) ¿Cuánto conversamos con nuestros hijos, estudiantes, familiares, etc...? En nuestra propuesta la conversación aparece desde el primer día, desde el nacimiento e incluso desde que Marcos estaba en el vientre materno. El principio se sustenta en la escucha mutua, en un diálogo, no erudito sino adaptado a la realidad contextual, a partir del cual se legitiman los que mantienen dicha conversación.

\section{Comenzando el misterioso viaje... El relato de la experiencia}

El único verdadero viaje de descubrimiento consiste no en buscar nuevos paisajes, sino en mirar con nuevos ojos. (Marcel Proust)

El descubrimiento requiere aceptar la incertidumbre propia de enfrentarse a lo desconocido, al novedoso viaje del aprendizaje. Los profesores y los estudiantes podemos saber, y sabemos, por dónde comienza el proceso educativo, pero nunca podemos tener la certeza de cómo concluirá. Dicha incertidumbre es la que nos permite focalizar nuestro viaje en el gozo del navegar, más que en el objetivo final resultante. La incertidumbre genera preguntas desafiantes que se convierten en gozo y disfrute cuando existen elementos de seguridad que nos permiten vivir dicha incertidumbre como un desafío. Y ese gozo (Imagen 1) es evidenciado, entre otras cosas, por el humor presente en la experiencia de aprendizaje.

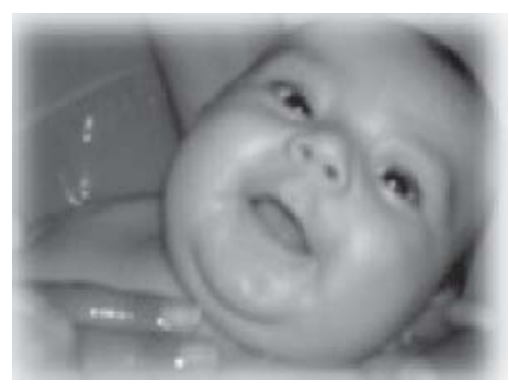

Imagen $1^{3}$ : Marcos disfrutando de la tina 


\section{Introduciéndonos en el medio acuático}

Esa seguridad de la que hablamos y que nos permite deambular en el gozo de lo incierto es generada, en nuestra propuesta, a partir de la comunidad familiar y la educación transgeneracional que ella nos brinda.
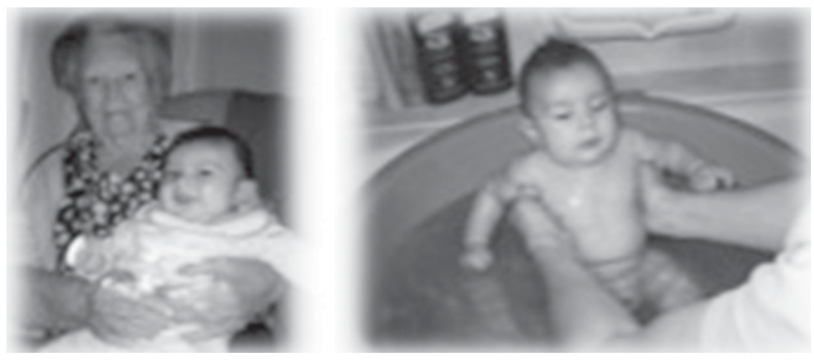

Imagen 2: Marcos con sus abuelas

Son las manos de la bisabuela y abuela (Imagen 2) las que le permiten, a Marcos, uno de sus primeros contactos con el medio acuático. No sólo por el aporte que dichas familiares pueden otorgarle al pequeño, sino también por lo que Marcos va a ser capaz de ofrecer, desde su relacionalidad amorosa, a ellas. Intencionamos un proceso a partir del cual todos aquellos implicados en el aprendizaje contribuyen y se enriquecen de su participación en el mismo.

Es en el juego (Toro, 2005) desde donde comenzamos a vertebrar la relacionalidad presente en la comunidad y el aprendizaje del infante, el juego como principio existencial pedagógico. El juego en un mundo desconocido, el medio acuático, nos permite, a partir de la introducción de elementos familiares en el mismo (Imagen 3), convertir la incertidumbre en un gozo desafiante.

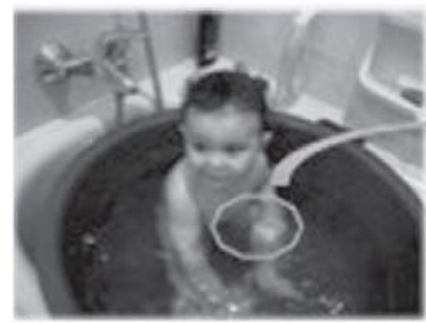

Elementos familiares en un contexto incierto

Imagen 3: Marcos jugando en la tina con los juguetes con los que más juega fuera del agua 
Es desde la familiaridad gozosa con este medio que comenzamos a proyectar un primer contacto con la inmensidad del medio acuático, ya no en la tina, sino en el contexto real de aprendizaje. El primer contacto con la inmensidad a la que hacemos referencia, es un proceso totalmente planificado pero en donde dicha planificación se constituye en un faro para la navegación. Nos permite direccionarnos pero si nos acercamos demasiado nos deslumbramos y podemos perder el control ${ }^{4}$. Es decir, la planificación de dicho primer contacto está ordenada e intencionada pero será el mismo infante quien decidirá si seguimos adelante con dicho contacto en función de la seguridad que sienta o si es mejor dejarlo para otra oportunidad.
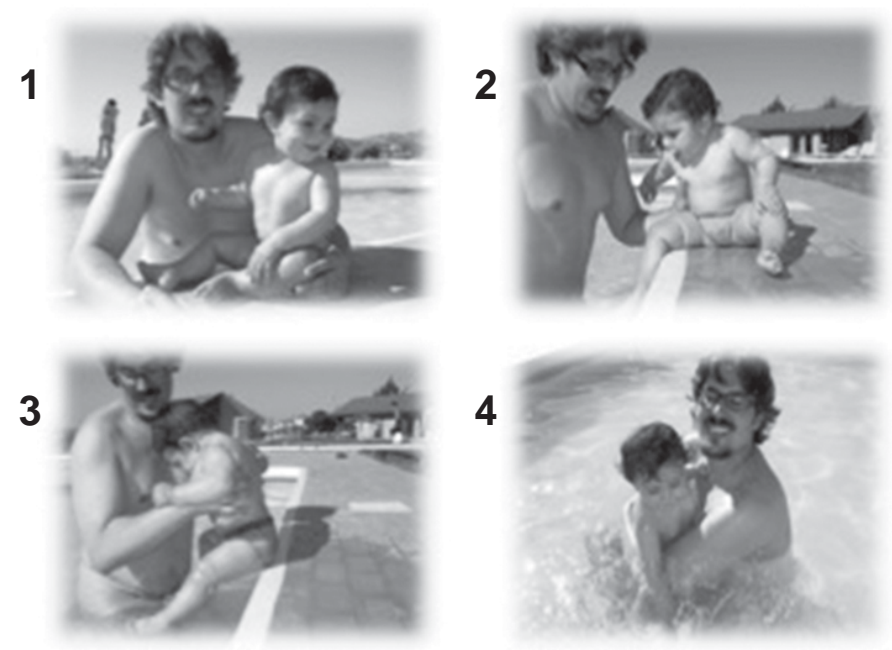

\section{Imagen 4: Marcos decidiendo ingresar a la inmensidad del medio acuático}

Él define hasta dónde llegar. Tenemos todo planificado pero él nos va diciendo hasta dónde se siente capaz. En un primer momento lo acercamos a lo que será el contexto que queremos que se constituya en el lugar donde Marcos adquiera autonomía. Seguidamente esperamos su respuesta al respecto. Él decide introducir uno de sus pies. Es ahí cuando el educador, percibiendo la seguridad del infante, decide dar un paso más. Quedamos a la espera de que Marcos siga queriendo introducirse en la inmensidad incierta de un medio novedoso. Dado que eso es así, comienzan a disfrutar (educador y educando) de las maravillosas y enriquecedoras experiencias que emergen de lo desconocido (Imagen 4).

Los educadores y profesores de educación física sabemos que el proceso pedagógico no puede estancarse en un nivel de dificultad siempre 
homogéneo sino que, por el contrario, debemos intencionar mayores niveles de complejidad cuando observamos seguridad y alto nivel de destreza en aquello que los educandos están realizando. A ello nos ayuda mucho la variabilidad del contexto de práctica.

La incertidumbre lleva asociada una sorpresa ante lo desconocido, y esa sorpresa o riesgo que los niños propenden a vivenciar les permiten un disfrute más allá de la actividad en si', pues en ella esta' implícita el placer por lo nuevo, por lo imprevisto, pocas veces presentes en las actividades escolares. Esta es una expresión de la transcendencia que buscan en su actuar. Transcendencia que se expresa en intentar ir más allá cada cierto tiempo, excepto cuando necesitan reforzar un nuevo conocimiento (Moreno, 2005: 9)

Es por ello que después de un tiempo (meses e incluso años) procedemos a ofrecer dicha variabilidad a Marcos (Imagen 5), en la intención de no estancar su aprendizaje en la certidumbre de lo aprendido. Es ahora el río y la playa los contextos que nos posibilitan dicha variabilidad.
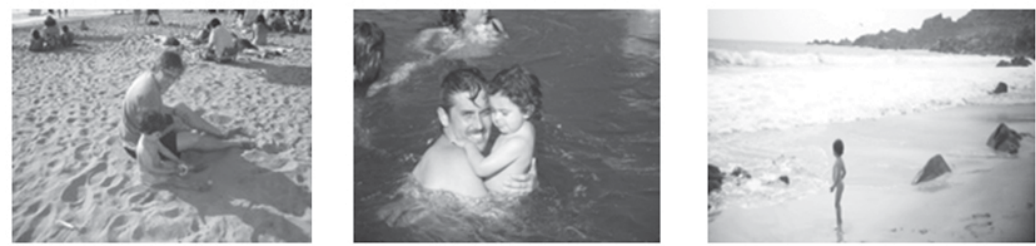

Imagen 5: Marcos en medios acuáticos diferenciados por sus contextos.

Consideramos que esta variabilidad del contexto ayuda al infante a cuestionarse, consciente o inconscientemente, lo que está viviendo.

Intentando ordenar y sistematizar lo relatado, nos preguntamos: ¿qué hemos hecho hasta aquí?:

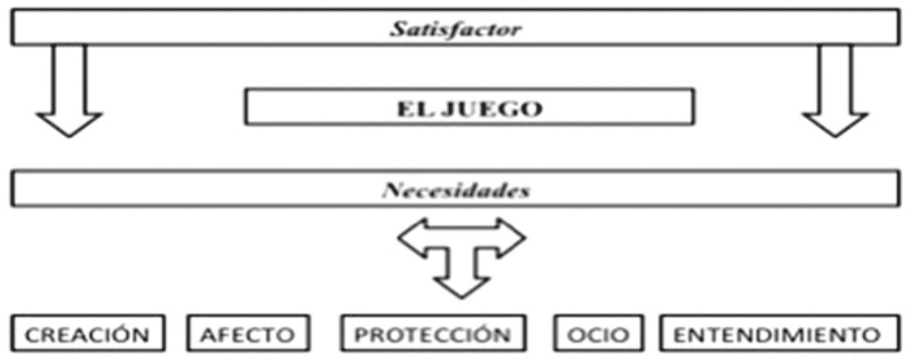

Imagen 6: elaboración propia 
El juego, nuestro satisfactor sinérgico, ha sido utilizado para el desarrollo sinérgico de varias necesidades: creación, afecto, protección, ocio y entendimiento (Imagen 6). A nuestro entender y tras años de experiencias educativas-investigativas, consideramos que este es uno de los ejes centrales de la labor pedagógica: las herramientas que utilicemos deben conducirnos hacia el trabajo de las diferentes necesidades humanas, dirigidas hacia el buen vivir ${ }^{5}$.

Ahora bien, el aprendizaje de la autonomía en el medio acuático, como mencionamos más arriba, no requiere de estar siempre y únicamente en dicho medio. La autonomía requiere de conocimientos, y en la construcción de los mismos juega un papel primordial la pregunta como germen de su construcción.

\section{Saliendo del medio acuático... pero estando aún en él}

Es la pregunta la que nos invita a conocer, la que dirige por ese misterioso viaje del aprendizaje (Freire, 1975) y desde aquí que acogemos las preguntas de Marcos en su diario vivir. Surge entonces la primera pregunta. ¿Cómo nadan los peces? La mediación pedagógica hace presencia entonces. ¿Cómo crees tú que lo hacen? ${ }^{6}$ Con su cuerpo, lo mueven muy rápido con las aletas, como Nemo. La respuesta de Marcos es un regalo para el educador, pues permite seguir implicados en la construcción del saber. ¿Quién es Nemo? Es un pez payaso. Vuelve la pregunta del educador ¿Un payaso que es un pez? Es un pez que tiene líneas ¿Cuántas líneas tiene? No sé, no sé... dice él.

Ante el reconocimiento de la ignorancia tampoco es adecuado, educativamente, dar por concluído el diálogo. Por el contrario, incentivamos ahora un proceso que le posibilite al infante, desde el reconocimiento de su propia ignorancia (Freire, 1975) una posible experiencia de éxito (Feuerstein et al., 1991) que provoque la continuidad en el entusiasmo por el desafío del aprendizaje. Vuelve la pregunta como eje vertebrador de la experiencia educativa. ¿Qué otros animales conoces que tengan líneas? La cebra, responde él. ¿En qué se parece una cebra a Nemo? Regresa el silencio.

Pero nos dejó implicados con una realidad infantil: NEMO. ¿Veamos la película de Nemo? Sí... Visionar la película no es sólo un medio de disfrute, sino que está acompañado de una intencionalidad pedagógica por parte del mediador, intencionalidad desconocida para Marcos pero que dirige el proceso de ver el video. ¿Contemos las líneas de Nemo? ¿Identifiquemos los colores? ¿Cuántas líneas existen de cada color? Es posible observar como a partir de estas preguntas estamos complejizando el aprendizaje y adentrándonos en las nociones básicas del cálculo (seriación y conteo) y en el desarrollo de operaciones mentales como la identificación y comparación (Feuerstein et al., 1991).

Los que han visto la película de la que hablamos, saben que en un 
pasaje de la misma raptan a Nemo. Dicha situación dirige a Marcos, emocional y lógicamente, hacia un profundo llanto. Situación que nos permite acogerlo en toda su legitimidad (Maturana, 2007) pero que no nos paraliza en nuestro proceso educativo, como suele ocurrir desde visiones paternalistas del quehacer pedagógico (Martín, 2011) Una vez tranquilizado desde la seguridad emocional que le ofrecemos, regresamos al proceso dialógico. ¿Por qué atrapan a Nemo? Es que se pelea con su padre. ¿Por qué se pelean? Es que Nemo quería hacer algo que su papá no le permitía ¿Por qué no le dejaba? Porque era peligroso. Surge ahora la genialidad infantil. ¿Tú que hubieras hecho si fueras el padre de Nemo? El silencio regresa. Pero este es un silencio no proveniente de la ignorancia por la respuesta, sino determinado por la posibilidad de comprometerse a algo por lo que después deberá dar explicaciones. Si Marcos responde que él le hubiese hecho caso a sus papás, eso significaría que sus padres podrían decirle: ¡¡dijiste que le ibas a hacer caso a tus padres!!! Es mejor callar entonces.

El proceso de mediación pedagógica no termina nunca. Intencionando un mayor nivel de complejidad en la tarea, a partir de un mayor nivel de abstracción en el aprendizaje, se le pregunta a Marcos si desea observar un libro de Nemo. Su respuesta afirmativa nos conduce a un nuevo desafío pedagógico: familiarizarlo con la biblioteca escolar en el entendido que puede ser el primer paso para el acceso a la cultura letrada. Ir a la biblioteca de su colegio conlleva un trabajo de coordinación con la bibliotecóloga, intencionando, junto a ella, un aprendizaje que nos conduzca a establecer criterios desde los cuales se pueda comprender cómo funcionan las bibliotecas. Y es aquí donde emerge, nuevamente, el trabajo comunitario. No desde la institución escolar hacia las familias, que suele ser lo habitual, sino desde la familia hacia la escuela, en el entendido que la educación de Marcos es una responsabilidad de ambas instituciones. Planificar la entrada al espacio de la biblioteca conlleva asumir que la misma debe convertirse en una experiencia exitosa de aprendizaje que pueda hacer que el infante se sienta entusiasmo por ese nuevo mundo lleno de libros, historias, imágenes y novedosos mundos por descubrir.

Ya en la biblioteca. ¿Dónde está el libro de Nemo? El juego de la búsqueda asistemática invita al educador a establecer criterios, junto al niño, que permitan entender cómo funcionan las bibliotecas. ¿Cómo buscar? ¿De arriba abajo? ¿De izquierda a derecha? ¿Qué significan los códigos que tienen los libros? Estos criterios permiten entender que el orden de los libros no es aleatorio. Es la exploración sistemática, una función cognitiva (Feuerstein et al., 1991), la que nos ocupa en esos momentos. Dicha exploración es una conducta transferible a cualquier situación de la cotidianeidad de Marcos. Por eso, al salir de la biblioteca y llegar a la casa continuamos practicando la exploración sistemática y el establecimiento de criterios para ordenarnos en el mundo (Imagen 7). 


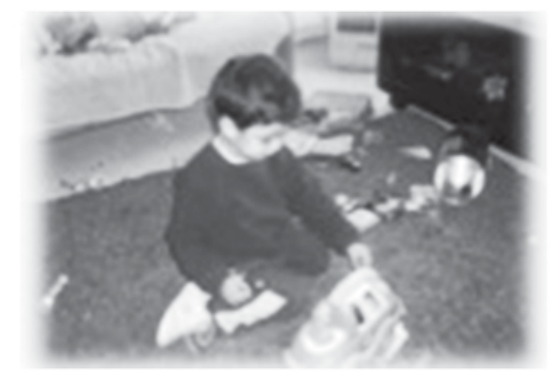

\section{Imagen 7: Marcos ordenando sus juguetes}

Y desde el ordenamiento nos adentramos entonces en nueva operación mental: la clasificación (Feuerstein et al., 1991). Utilizando los criterios ya aprendidos, preguntamos, ¿cómo ordenamos los juguetes? Los dinosaurios con los dinosaurios, los verdes con los verdes, los amarillos con los amarillos...

\section{Regresando al medio acuático}

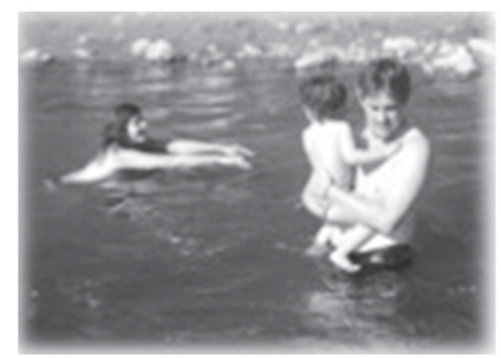

\section{Imagen 8: Marcos observando como su madre disfruta del medio acuático}

Nuevamente en el medio acuático, utilizamos un recurso (probablemente cuestionado por algunos) que nos resulta altamente eficaz y educativo. Generar autonomía en el medio acuático, como cualquier aprendizaje, requiere que el aprendiz sienta la necesidad de adentrarse en dicho aprendizaje. Es entonces que utilizamos el disfrute de otros en ese medio para que Marcos también quiera aprender. No es la envidia por lo que hace el otro, sino el deseo genuino por aprender lo que otros son capaces de realizar lo que nos motiva en esta parte del proceso. Es por ello que en la fotografía anterior pueden observar cómo la mamá del 
infante se desliza placenteramente por el agua ante los ojos de Marcos (Imagen 8). Y llega el mágico momento en donde él comienza a exigir querer hacer lo mismo. ¿Cómo hacerlo aceptando el riesgo que ello conlleva? Es aquí cuando la transformación del medio nos entrega variadas posibilidades.
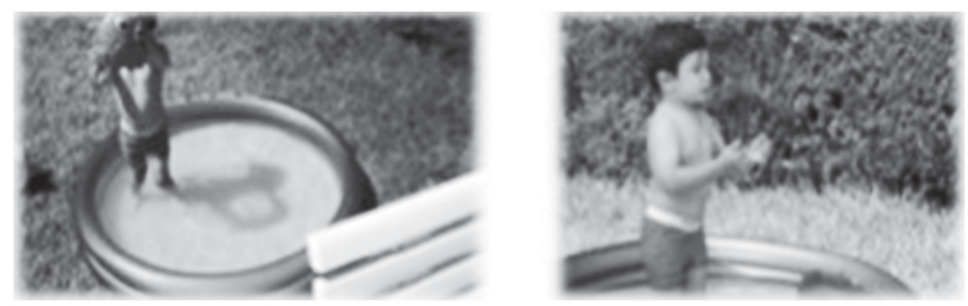

\section{Imagen 9: Marcos bañándose autónomamente en una piscina adecuada a su nivel de aprendizaje}

La necesidad de autonomía requiere usar una piscina muy pequeña para que pueda jugar, sin depender explícitamente de los otros. Pero a pesar de la seguridad planificada surgen los primeros conflictos, relacionados estos con la caída de agua en los ojos de Marcos, como se puede observar en la imagen 9. La certeza del no peligro le llevan a jugar gozosamente en el agua, adquiriendo nuevos riesgos y, lógicamente, haciendo emerger experiencias algo desagradables como la comentada. Es entonces cuando el educador advierte que para adquirir autonomía en el medio acuático requerimos de ese aprendizaje previo: ser capaz de que el agua caiga por su cara sin que ello se convierta en un impedimento para seguir en dicho medio. Vuelven entonces los elementos de seguridad que facilitarán dicho aprendizaje y en donde la comunidad vuelve a jugar un papel primordial.

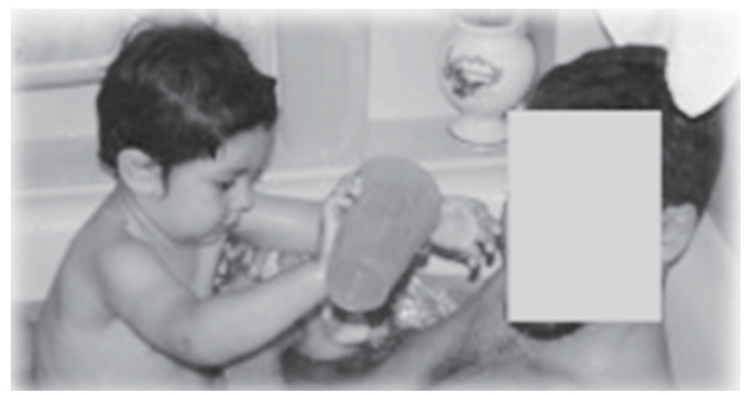

Imagen 10: Marcos jugando con su tío en la tina 
Es ahora su tío quien toma la iniciativa y decide (Imagen 10), habiendo planificado la tarea, adentrarse en la tina con el propósito central de que al salir de ella Marcos pueda disfrutar del agua en su cara. El juego es simple: consiste en que ambos deben echarse agua por la cara y reir por ello. El vínculo afectivo nos posibilita mayores cuotas de confianza que se convierten en el germen de novedosos aprendizajes

\section{Y de nuevo las preguntas}

¿Todos los animales nadan? ¿Has visto a un gato nadar? No... ¿A qué animales has visto nadar? Hay algunos dinosaurios que nadan. ¿Cuáles? Los tecodontosaurios. La sorpresa del educador en estos momentos es grande, pues asume su ignorancia, al no saber si existen esos dinosaurios o si es una invención de Marcos. Finalmente, tras la búsqueda correspondiente, puede comprobar su existencia ${ }^{7}$. ¿Quieres que veamos más dinoasaurios que nadan? Sí... Nuevamente emerge una experiencia muy enriquecedora desde el punto de vista educativo. Los libros se constituyen, otra vez, en un viaje hacia la cultura letrada. Pero no accedemos a la biblioteca, ya conocida, sino a un nuevo contexto donde también pueden ser encontrados los libros. Las librerías, espacio-tiempo de creatividad pero con criterios de funcionamiento diferente al de las bibliotecas (Imagen 11).

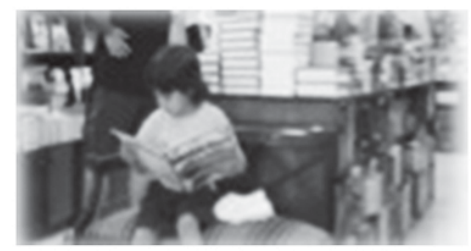

Imagen 11: Marcos en una librería

¿Papá, me puedes leer? Claro, leamos. ¿Qué recuerdas de lo que te he leído? Que hay diferentes tipos de dinosaurios. ¿Cuáles? Los que nadan, los que vuelan..

\section{Jugando con el lenguaje}

El lenguaje como parte sustancial del conocer humano (Maturana, 2002) nos permite seguir jugando y seguir profundizando en las operaciones mentales que los seres humanos poseen (Feuerstein et al., 1991). ¿Cómo se llaman los que nadan? Nadadores. ¿Y los que vuelan? Voladores. ¿Y los que se arrastran? La grandeza y riqueza del aprendizaje infantil reapare- 
ce nuevamente y nos sorprende por la facilidad con la que Marcos aprende un criterio, incorrecto pero lógico, respondiendo (pero preguntando), ¿arrastradores? La palabra arrastradores no le suena, aunque mantiene y cumple con el criterio a partir del cual había respondido anteriormente. El educador, entonces, corrige tajante pero cariñosamente. Reptiles. Ahhh, reptiles, como las serpientes. Marcos construye una nueva relación que conlleva, lógicamente, una nueva felicitación por parte del educador.

\section{Inmersos en el medio acuático, comienza a emerger el misterio}

Papá, ¿̇me dejas solo en el agua? El miedo del educador reaparece, dado el riesgo que lo planteado supone. El niño pide autonomía y el educador es ahora quien se siente inseguro. La experiencia es algo desagradable, pues no consigue realizarla exitosamente. Marcos requiere que el educador vaya hacia a él porque no consigue flotar en el medio acuático. Una vez pasada la desagradable experiencia, Marcos hace una nueva petición. Papá, ¿puedes comprarme un flotador? Sin duda que dicho instrumento le permitirá seguir disfrutando del medio acuático sin la necesidad de que el adulto esté siempre presente (Imagen 12).

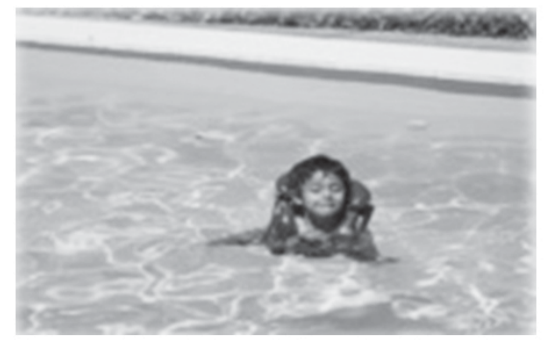

Imagen 12: Marcos con flotador en una piscina

Después de algún tiempo, meses, vuelve a emerger el misterio. Papá, ¿y si me quito el flotador podré nadar? Estoy seguro que sí (el educador mostrando altas expectativas por el aprendizaje del infante). Pero voy a probar en la parte en donde el agua no me cubre, ¿ vale? Y la magia se hace presente (Imagen 13). 


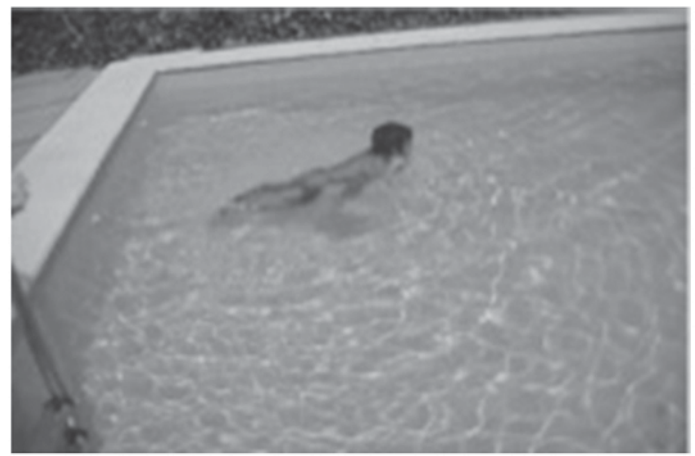

\section{Imagen 13: Marcos mostrando su autonomía en el medio acuático}

\section{Conclusiones para seguir el viaje}

La experiencia relatada nos permite compartir una serie de reflexiones con las que dar por terminado este trabajo pero que, a la vez, nos permiten seguir pensando, dialogando y construyendo nuevas posibilidades de acción para hacer de los procesos educativos caminos por los que transitar hacia mejores y mayores posibilidades para los más pequeños de este país. Las reflexiones son las siguientes:

La escuela no debe adueñarse de los procesos educativos, pero sí puede aprender de ellos para configurar procesos de aprendizajes al interior de sus aulas que abandonen, definitivamente, el paradigma dicotómico, excluyente, paternalista y superficial con el que suele sustentar sus prácticas de enseñanza.

La educación es un proceso de creación de relaciones posibles que nos invita a terminar con el asignaturismo aún existente en el proceso escolar, y que pretende hacernos entender el conocimiento como compartimentos estancos de los que se adueñan las diferentes disciplinas.

La capacidad de aprendizaje de niños y niñas depende, principal aunque no únicamente, de las posibilidades que el contexto les entregue y de los procesos de mediación que los educadores/as sean capaces de intencionar.

Desde una problemática concreta, en este caso motora, podemos generar un proceso de aprendizaje complejo, holístico y orientado desde las propias inquietudes de los infantes.

El aprendizaje dialógico supera la visión, aún psicologicista, del constructivismo pedagógico que aún sustenta el actual sistema educativo chileno. 


\section{Notas}

${ }^{1}$ Este artículo se ha realizado en el contexto y gracias al Proyecto de Investigación FONDECYT N ${ }^{\circ}$ 1110577, titulado Asombros Educativos Infantiles y Propensión a Aprender. Y dirigido por el Dr. Carlos Calvo Muñoz.

${ }^{2}$ Entendemos, siguiendo a Maturana (2002) que al aprendizaje es una característica biológicamente consustancial al ser humano.

${ }^{3}$ Importante mencionar que todas las imágenes que aquí aparecen son reales y productos del trabajo de campo realizado. Tenemos los permisos y consentimientos correspondientes para poder hacerlas públicas.

${ }^{4}$ Metáfora utilizada por el Dr. Carlos Calvo en algunas de sus publicaciones (Calvo, 2012).

${ }^{5}$ El concepto del buen vivir ha sido tomado de Rojas, 2011.

${ }^{6}$ Uno podría dar una respuesta cerrada, unívoca y certera. Pero eso daría por finalizado el viaje, el mar de posibilidades que genera el mismo proceso de preguntar.

${ }^{7}$ Thecodontosaurus (lagarto con dientes en cuencas) es un género representado por una única especie de dinosaurio sauropodomorfo tecodontosáurido, que vivió en el Triásico superior, en lo que hoy es Europa. Thecodontosaurus era un dinosaurio herbívoro que midió aproximadamente $1,20 \mathrm{~m}$ de largo, $30 \mathrm{~cm}$ de alto y un peso estimado de $11 \mathrm{~kg}$. Poseía un cráneo estrecho dotado de dientes curvos. El tecodontosaurio podía desplazarse tanto de forma bípeda como cuadrúpeda. Es considerado herbívoro y, a veces omnívoro por el detalle semiafilado de sus dientes (http://es.wikipedia.org/ wiki/Herb\%C3\%Advoro). 


\section{Bibliografía}

Aubert, A., et, al. (2010), Aprendizaje dialógico en la sociedad de la información, Editorial Hipatia, Barcelona.

Calvo, C. (2012), Del mapa escolar al territorio educativo. Disoñando la escuela desde la educación, Universidad de La Serena, La Serena.

Díaz, C., et. al. (2010), “Los docentes en la sociedad actual: sus creencias y congniciones pedagógicas respecto al proceso didáctico”, en Polis, Revista Latinoamericana 9, 25, 421-436, Santiago de Chile.

Feuerstein, R., et., al. (1991), Mediated Learning Experiencie: theoretical, psychosocial and learning implications, Freund Publishing House, London.

Freire, P. (1975), Pedagogía del Oprimido, Siglo XXI, Madrid.

Gutiérrez, F. (2007), “Educación en el paradigma emergente”, en Revista Cooperación Educativa Kikiriki 84, 29-33, Sevilla.

Idem (2010), “Las nuevas ciencias de la vida”, en Polis, Revista Latinoamericana, 9, 25, 223-233, Santiago de Chile.

López de Maturana, S. (2009), Los buenos profesores: educadores comprometidos con un proyecto educativo, Universidad de La Serena, La Serena.

López, V., et. al. (2002), “Algunas reflexiones sobre educación física y pedagogía crítica”, en Retos, 2, 30-35, Murcia.

Martín, J. (2011), “Los errores del actual sistema educativo”, en Foro de Educación, 13, 253-256, Salamanca.

Maturana, H. (2006), Desde la biología a la psicología, Editorial Universitaria, Santiago de Chile.

Ídem (2007), El sentido de lo humano, Dolmen, Santiago de Chile.

Maturana, H. y Varela, F. (2002), El árbol del conocimiento: las bases biológicas del entendimiento humano, Lumen ,Buenos Aires.

Max Neef, M.; Elizalde, A. y Hopenhayn, M. (1998), Desarrollo a escala humana. Conceptos, aplicaciones y algunas reflexiones, Nordan Comunidad, Montevideo.

Moreno, A. (2005), “La realidad etnoeducativa en una comunidad mapuche: un análisis descriptivo”, Revista Organización Estados Iberoamericanos, 37, 1-15, Madrid. 
Ídem (2006), Teoría del caos y educación informal, Editorial Hergué, Huelva.

Moreno, A. y Calvo, C. (2010), “Etnoeducación, educación física y escuela. Transitando desde la educación informal a la escuela autoorganizada”, en Ágora para la Educación Física y el Deporte, 12, 2, 131-150, Valladolid.

Ojeda, C. (2001), "Francisco Varela y las ciencias cognitivas”, en Revista chilena de neuro-psiquiatria, 39, 4, 286-295, Santiago de Chile.

Ortiz, M. (2009), El proyecto de autonomía, en http:// educautonomia.blogspot.com/2009/06/francisco-varela-y-el-proyectode.html

Pastor, J. (2007), “Fundamentación epistemológica e identidad de la educación física”, en Profesorado. Revista de currículum y formación del profesorado, 11, 2, 1-17, Granada.

Rojas, G. (2011), La vida y sus encrucijadas. Un camino para el buen vivir, Instituto Internacional del Saber, España-Colombia.

Santos, M. (2004), “Arqueología de los sentimientos en la organización escolar”, en Tendencias Pedagógicas, 9, 45-69, Madrid.

Toro, S. (2005), Una aproximación epistemológica a la didáctica de la motricidad desde el discurso y práctica docente, Tesis de Doctorado en Ciencias de la Educación, Facultad de Educación, Pontificia Universidad Católica de Chile, Santiago de Chile.

Varela, F. (2000), El fenómeno de la vida, Dolmen, Santiago de Chile.

Recibido: 18.12 .2013

Aceptado: 09.02.2014 